\title{
BMJ Open Pregnancy anaemia, child health and development: a cohort study in rural India
}

\author{
Esther Heesemann (D , , ${ }^{1,2}$ Claudia Mähler, ${ }^{3}$ Malavika A Subramanyam, ${ }^{4}$ \\ Sebastian Vollmer ${ }^{5}$
}

To cite: Heesemann E, Mähler C, Subramanyam MA, et al. Pregnancy anaemia, child health and development: a cohort study in rural India. BMJ Open 2021;11:e046802. doi:10.1136/ bmjopen-2020-046802

- Prepublication history and additional supplemental material for this paper are available online. To view these files, please visit the journal online (http://dx.doi.org/10.1136/ bmjopen-2020-046802).

Received 10 November 2020 Accepted 24 August 2021

Check for updates

(c) Author(s) (or their employer(s)) 2021. Re-use permitted under CC BY-NC. No commercial re-use. See rights and permissions. Published by BMJ.

${ }^{1}$ Department of Economics, University of Mannheim, Mannheim, Germany

${ }^{2}$ Center for Evaluation and Development, Mannheim, Germany

${ }^{3}$ Institute for Psychology, University of Hildesheim, Hildesheim, Niedersachsen, Germany

${ }^{4}$ Social Epidemiology, ITT Gandhinagar, Gandhinagar,

Gujarat, India

${ }^{5}$ Department of Development Economics, Center for Modern Indian Studies, University of Göttingen, Goettingen, Niedersachsen, Germany

Correspondence to Sebastian Vollmer; svollmer@uni-goettingen.de and Esther Heesemann; esther.heesemann@gmail.com

\section{ABSTRACT}

Objective To assess how pregnancy anaemia affects the offspring's early childhood development, child haemoglobin $(\mathrm{Hb})$ levels child growth and diseases incidence 2 years after birth in a low-income setting. Furthermore, we investigate the mediating role of childhood $\mathrm{Hb}$ levels with disease incidences and skills. Design Prospective cohort study.

Setting and participants The study participants are 941-999 mother-child dyads from rural Madhepura in Bihar, India. In 2015, the women were recruited during pregnancy from registers in mother-child centres of 140 villages for the first wave of data collection. At the time of the second wave in 2017, the children were 22-32 months old.

Primary and secondary outcome measures The recruited women were visited at home for a household survey and the measurement of the women's and child's $\mathrm{Hb}$ level, child weight and height. Data on the incidence of diarrhoea and respiratory diseases or fever were collected from interviews with the mothers. To test motor, cognitive, language and socioemotional skills of the children, we used an adapted version of the child development assessment FREDI.

Results The average $\mathrm{Hb}$ during pregnancy was $10.2 \mathrm{~g} /$ $\mathrm{dL}$ and $69 \%$ of the women had pregnancy anaemia. At the age of 22-32 months, a $1 \mathrm{~g} / \mathrm{dL}$ increase in $\mathrm{Hb}$ during pregnancy was associated with a $0.17 \mathrm{~g} / \mathrm{dL}(95 \% \mathrm{Cl}: 0.11$ to 0.23 ) increase in $\mathrm{Hb}$ levels of the child. Children of moderately or severely anaemic women during pregnancy showed $0.57 \mathrm{~g} / \mathrm{dL}(95 \% \mathrm{Cl}:-0.78$ to -0.36$)$ lower $\mathrm{Hb}$ than children of non-anaemic women. We find no association between the maternal $\mathrm{Hb}$ during pregnancy and early skills, stunting, wasting, underweight or disease incidence. While childhood anaemia does not correlate with childhood diseases, we find an association of a $1 \mathrm{~g} / \mathrm{dl}$ increase in the child's Hb with 0.04 SDs higher test scores.

Conclusions While pregnancy anaemia is a risk factor for anaemia during childhood, we do not find evidence for an increased risk of infectious diseases or early childhood development delays.

\section{INTRODUCTION}

Sufficient intake of macronutrients and micronutrients during pregnancy is a prerequisite for healthy child development. ${ }^{1}$ Yet, the high rates of pregnancy anaemia, that is,

\section{STRENGTHS AND LIMITATIONS OF THIS STUDY}

$\Rightarrow$ The study used a unique cohort of pregnant women and their 2-year-old children.

$\Rightarrow$ We controlled for maternal haemoglobin $(\mathrm{Hb})$ and household food security after pregnancy, together with other relevant confounding factors.

$\Rightarrow$ The data contain only one measure of $\mathrm{Hb}$ during pregnancy and the attrition between the waves is high.

having a low level of haemoglobin (Hb) level in the blood, document the precarious state of nutrition among many pregnant women worldwide. In 2011, 32 million women were estimated to be anaemic, the vast majority living in South Asia. ${ }^{2}$ A focus on anaemia is imperative because $\mathrm{Hb}$ is a crucial ingredient of red blood cells and thereby responsible for the transport of oxygen to the body tissues. Low $\mathrm{Hb}$ during pregnancy is a known risk factor for premature birth, low birth weight and in extreme cases leads to death. ${ }^{3-7}$ Yet, also high $\mathrm{Hb}$ levels, especially in the first trimester, are associated with adverse birth outcomes, suggesting a U-shaped relationship. ${ }^{8}$ One of the most common causes of anaemia in low-income and middle-income countries, such as India, is iron deficiency. ${ }^{9} 10$ Anaemia can however also result from other micronutrient deficiencies such as folic acid, vitamin $\mathrm{B} 12$ and vitamin $\mathrm{A}$, as well as infectious diseases and genetic disorders.

In this paper, we investigate the consequences of pregnancy anaemia on child $\mathrm{Hb}$ levels, early skills and other health indicators in the first 1000 days. With a prevalence of $58 \%$, anaemia of children below the age of 5 remains a significant global health challenge in South Asia and its causes are worth investigating. ${ }^{2}$ The known adverse consequences of childhood anaemia on human development, in particular cognitive skills, add importance to this matter. ${ }^{11-13}$ Most of the iron requirement in the first year of life is met by the 
body iron a child is born with, either in the form of $\mathrm{Hb}$ or in iron stores (ferritin). The amount of ferritin and $\mathrm{Hb}$ at birth depends heavily on the iron transfer from mother to child in-utero, which occurs in the second and third trimesters of pregnancy. ${ }^{14}$ Studies have shown that anaemia during pregnancy correlates with low cord $\mathrm{Hb}$ levels and anaemia during infancy. ${ }^{11}{ }^{15-19}$ To the best of our knowledge, there are no studies investigating the relationship of pregnancy anaemia and anaemia of children older than 18 months.

While several experimental and non-experimental studies have examined the impact of pregnancy anaemia or iron deficiency on early skills, the empirical findings are inconclusive. ${ }^{20}{ }^{21}$ This might be a result of different study designs, age variation of the study participants, the dimensions of skills measured or geographical diversity. ${ }^{22-29}$ Furthermore, as pregnancy anaemia is a risk for adverse birth outcomes, the existing experimental studies exclude moderately and severely anaemic women from the trials. Hence, the external validity of their findings for the general population of pregnant women is unclear. Observational studies without the appropriate quasiexperimental methods are unable to identify a causal impact of anaemia during pregnancy on child outcomes due to omitted, endogenous variables. For instance, ignoring time-invariant environmental factors is likely to upwardly bias the results of non-experimental studies.

We contribute to the existing literature by analysing the consequences of pregnancy anaemia on child outcomes in three essential ways. First, we eliminate an important confounder in the analysis by controlling for the maternal $\mathrm{Hb}$ levels and the food diversity of the household after birth. While not being able to fully capture the unobservable differences between children exposed to pregnancy anaemia and without, our set of covariates will omit the bias emerging from differences in micronutrient diversity in the postnatal period. Second, by following the children more than 2 years after birth, we can observe if potential initial disadvantages persisted over time. Finally, in addition to cognitive and non-cognitive functions, and anaemia, we also assess the influence of pregnancy anaemia on secondary health outcomes, namely child growth and disease incidence. This analysis will help to get a deeper understanding of the adverse consequences of anaemia during pregnancy.

\section{METHODS}

\section{Data and procedures}

Our data set is a panel of two waves, consisting of household surveys, anthropometric and blood sample collections and child development tests conducted in Madhepura in the North-Eastern state Bihar. Bihar is one of the poorest states of India and Madhepura belongs to its socioeconomically most deprived districts. Our study sample was taken from pregnancy registers in local mother-child-centres (Anganwadi centres) in 140 villages in six subdistricts (blocks) of Madhepura. It should hence be noted that our sample is not representative of the full population of pregnant women in that area, but only for those who registered in the centres. In 2015/2016, this covered $76 \%$ of pregnant women. ${ }^{30}$

All women listed in the registries in March/April 2015 were visited by teams of trained, local survey enumerators, medical data collectors and child development testers, and invited to participate in the baseline survey and medical tests. During the follow-up in November/ December 2017, we attempted to revisit the households of all formerly pregnant women. In addition to the survey and medical measures for mothers and children, a development test was administered to the child that resulted from the pregnancy. The household survey, the medical measurements and the child development test were conducted within oneweek for each household. Online supplemental figure $\mathrm{S} 1$ visualises the data collection timeline, the age of the children and the gestational stage of the women during the data collections.

\section{Outcome measures}

Anaemia is defined over the $\mathrm{Hb}$ level in the blood, which in our case was obtained from a finger prick in the respondents' homes, collected by trained local enumerators. Using point-of-care HemoCue 301 machines for capillary blood, the $\mathrm{Hb}$ level can be determined immediately and communicated to the tested individual or its caregivers on the spot. ${ }^{31}$ (The bias of HemoCue 301 anaemia assessments compared with laboratory tests is with $0.25 \mathrm{~g} /$ $\mathrm{dL}$ well below the WHO recommended threshold for point-of-care machines.) According to the WHO and the Indian Council of Medical Research definitions, a pregnant woman is anaemic if her $\mathrm{Hb}$ concentration falls below $11.0 \mathrm{~g} / \mathrm{dL} .{ }^{32}{ }^{33}$ Pregnancy anaemia is further distinguished into mild anaemia $(10.0-10.9 \mathrm{~g} / \mathrm{dL})$, moderate anaemia $(7.0-9.9 \mathrm{~g} / \mathrm{dL})$ and severe anaemia $(<7.0 \mathrm{~g} / \mathrm{dL})$. The anaemia thresholds for children between 6 and 59 months are the same as for pregnant women. ${ }^{33}$

During data collections, the field teams followed a strict protocol on detection of anaemia. In case of mild or moderate anaemia, the women/caregivers were advised to go to the nearest primary healthcare centre soon to seek treatment for anaemia. In case of severe anaemia, the household was alerted that immediate attention was needed. In the follow-up survey, we also offered to cover the treatment costs and transport to a health facility for all severely anaemic children.

Child development was measured with a variation of the FREDI 0-3, a German development test similar in structure to the Bayles Scales of Infant and Toddler Development. ${ }^{34-36}$ Due to the different home environments of the children, certain items of the original FREDI 0-3 were adjusted to the Bihari context. The development test consists of a parent questionnaire and a child assessment, and covers four areas: fine and gross motor development, receptive and expressive language development, cognition and socioemotional development. Two age-specific tests were administered, each covering skills over an 
age range of 5 months. Each test consisted of around 40 items. All raw scores have been standard normalised and are hence presented as z-scores. In addition to the four individual test scores, we calculate the total FREDI z-score over all 40 test items. A brief validation of the FREDI with regard to physical growth and maternal education is presented in online supplemental figures S2 and 3).

Stunting (ie, being too short for their age), wasting (ie, being too light for their height) and underweight (ie, being too light for their age) are used as secondary health outcomes. Children's height and weight were measured during the field visits by the medical testing team. We agestandardised the raw height and weight values following the WHO Growth Standards. ${ }^{37}$ With a respective z-score of 2 SD below the median of the WHO references population, a child is defined as being either stunted, wasted or underweight. Any value above $6 \mathrm{SD}$ or below $6 \mathrm{SD}$ was coded as measurement error and dropped from the analyses. (This was the case for 21 weight-for-height z-scores, 7 weight-for-age z-scores and 11 height-for-age z-scores.) The information on diarrhoea and respiratory disease or fever incidences in the 2 weeks before the survey were collected from maternal reports during the household survey and coded as binary variables.

\section{Patient and public involvement}

The aims and the survey design were shared at a meeting of state- and district-level government officials who provided services in Madhepura through the Women and Child Development ministry, village-level leaders of women's groups prior to the baseline. At this meeting, there was a detailed discussion of the types of questions that needed to be asked during the data collection. Several of these suggestions were incorporated in the baseline questionnaire. Residents of Madhepura were involved to the extent that they participated in the pretesting of the baseline questionnaire and the FREDI tool. Patients had not been involved in the interpretation of results, writing or editing of the final document.

\section{Statistical analysis}

In our main analysis, we estimated the association between pregnancy anaemia and the child $\mathrm{Hb}$ level and child development approximately 2 years after birth using an ordinary least-square regression model. Our secondary outcomes of interest, being stunted, wasted or underweight, incidence of diarrhoea and respiratory diseases or fever in the 2 weeks before the survey, were analysed with a logistical regression model.

We considered both continuous and discrete Hb levels to allow for linear and non-linear relationships between pregnancy anaemia and the child outcomes. For the linear relationship, our explanatory variable of interest was the $\mathrm{Hb}$ levels of the women during pregnancy, measured at the time of the baseline data collection. For the non-linear relationship, we used the expressions of anaemia status as predictors: no pregnancy anaemia, mild pregnancy anaemia and moderate-to-severe pregnancy anaemia. Dummy variables were created for no, mild, and moderate-to-severe anaemia, and simultaneously added to the regression equation. No anaemia served as the reference category. To test a possible U-shaped relationship between pregnancy $\mathrm{Hb}$ and the primary child outcomes, we included a quadratic term to the linear regression model.

All estimations controlled for the maternal $\mathrm{Hb}$ levels and the household food diversity scores at the time of the follow-up. This was done to avoid an overestimation of the relationship between pregnancy and child outcomes due to an overall poor food environment or chronic diseases of the mothers. Overall poor household nutrition during childhood is likely to correlate with a poor nutrition of women during pregnancy. As both factors are likely to adversely affect child health and development, ignoring the nutritional environment at the time of the outcome measure might lead to an overestimation of the correlation of pregnancy anaemia and child well-being. We further add age, sex and current breast-feeding status of the child, as well as development test facilitator (FREDI fixed effects) or HemoCue machine/medical tester fixed effects as control variables to obtain more precise estimates. Additional covariates from the baseline data relate to the socioeconomic status of the household (caste category, wealth quintile and maternal literacy) and pregnancy characteristics which might be correlated with both the Hb levels during pregnancy and child outcomes (maternal age, pregnancy history (first birth dummy), trimester of gestation at the time of the $\mathrm{Hb}$ measurement and take-up of antenatal care (ANC) services). (To test the robustness of our findings, we also conducted an analysis in which we replaced gestational trimester during pregnancy $\mathrm{Hb}$ measurement with the gestational months, and a subsample analysis for each of the three gestational trimesters during the pregnancy $\mathrm{Hb}$ measurements.) Finally, we added subdistrict (block) fixed effects and clustered the SEs on village level to take spatial correlation of the outcome variables into account. For the sensitivity analysis, we included birth spacing, macronutrient deficiency and postnatal depression to the estimation and replaced block with panchayat fixed effects. (We did not include those variables in the main specification due to missing information, which would have further reduced the sample size. A panchayat is a subdivision of a block and comprises several villages.)

In light of strong son preferences in the study region, ${ }^{3839}$ we investigated heterogeneous effects for boys and girls. Furthermore, we tested for heterogeneous effects by ANC take-up, as a proxy for health preferences, caste categories, maternal literacy levels and gestational trimester at the time of the baseline survey.

As child anaemia could be a result as well as a mediator for pregnancy anaemia, we investigated the association of childhood $\mathrm{Hb}$ levels with early childhood development and infectious diseases in separate analyses. Using the same set of covariates as described above, we controlled for household level and child specific characteristics that 
might affect both child $\mathrm{Hb}$ levels and the outcome variables of interest.

Finally, given the existing evidence of maternal anaemia for adverse pregnancy outcomes, we conducted a survival analysis that assessed whether the $\mathrm{Hb}$ level of pregnant women correlates with child loss. Such a correlation would downward bias the estimates of our main analysis, as the most deprieved children would systematically be missing in the group with higher exposure. We tested this hypothesis by estimating a probit model for non-survival on the pregnancy anaemia and Hb levels.

All estimations were weighted with inverse probability weight, as proposed by Fitzgerald, Gottschalk and Moffitt (1998) adjusting the sample for selective attrition between the waves. ${ }^{40}$ The statistical analyses were conducted with the statistical software Stata V.16 (StataCorp LP).

\section{RESULTS}

\section{Sample description}

The final sample consisted of 941-1000 mother-childdyads, depending on the outcome variable. We calculated an unadjusted minimum detectable effect of $0.22 \mathrm{~g} /$ $\mathrm{dL}$ for child $\mathrm{Hb}$ and $0.12 \mathrm{SD}$ for skill outcomes, statistically significant at the $10 \%$ level, comparing children of mothers with mild or moderate pregnancy anaemia to children of mothers without pregnancy anaemia. At the time of the endline data collection in 2017, the age of the children lied between 22 and 32 months.

Table 1 presents the explanatory variable, covariates and the outcome variables of interest of the estimation sample separately for three anaemia categories: no pregnancy anaemia (columns 1-3), mild pregnancy anaemia (columns 4-6) and moderate-to-severe pregnancy anaemia (columns 7-9).

The distribution shown in the table is suggestive of a gradient in child $\mathrm{Hb}$ levels and growth indicators across pregnancy anaemia levels. We do not observe a clear trend for the skill outcomes or disease incidences. Interestingly, the distribution of $\mathrm{Hb}$ levels of women after pregnancy across the anaemia groups mirrors the $\mathrm{Hb}$ levels during pregnancy suggesting that suboptimal micronutrient intake during pregnancy continued after delivery. This is however not the case for the household food diversity scores, which is the highest for the mild pregnancy anaemia group.

The majority of women in our sample $(69 \%)$ were at least mildly or moderately anaemic during pregnancy, with an average $\mathrm{Hb}$ level of $10.2 \mathrm{~g} / \mathrm{dL}$. Of all anaemic women, $48 \%$ showed signs of moderate anaemia, and only $4 \%$ severe anaemia. Less than $2 \%$ of women had $\mathrm{Hb}$ level above $13 \mathrm{~g} / \mathrm{dL}$, which can be considered as high. Overall, the literacy level of the study population was low with a quarter of the women being able to read and write, similar in all three presented anaemia groups. Such low levels of literacy are comparable with district-wide statistics of a nationally representative survey from 2015 to $2016 .{ }^{30}$ Women with more severe pregnancy anaemia were on average in a higher gestational trimester at the time of measurement. This is unsurprising considering the elevated iron needs as pregnancy progresses. Yet as gestational trimester also correlates with child age, which might affect the development test outcomes and anaemia status, we controled for gestational trimester in all estimations, to avoid biases. Importantly, half of the women reported not having received any ANC during pregnancy. This figure sets our sample strongly apart from most existing studies, many of which recruited their participants during ANC visits ${ }^{22} 2841$ or delivered ANC visits as part of the study. ${ }^{27}$ The uptake of ANC services is the highest in the group of moderate or severe pregnancy anaemia and lowest for women of mild pregnancy anaemia.

The sample size during follow-up data collection reduced considerably from the baseline $(n=1918)$ due to the unavailability of the women or children at the time follow-up visits, inaccurate location information, refusal to provide a blood sample or to participate in the child testing and child death (figure 1). We account for this loss in sample size by using inverse probability weights in all estimations, assigning higher weights to those households that had a higher probability of dropping out. (Relevant weighting variables were used despite missing information, which reduces the estimation samples by two more observations.).

\section{Association of pregnancy anaemia with childhood anaemia and early skills}

We found a strong association of Hb during pregnancy, mild and moderate or severe pregnancy anaemia with the child's $\mathrm{Hb}$ levels (table 2). An increase of $1 \mathrm{~g} / \mathrm{dL}$ in $\mathrm{Hb}$ during pregnancy was associated with $0.17 \mathrm{~g} / \mathrm{dL}$ higher $\mathrm{Hb}$ levels in the offspring. Children born to women with mild anaemia had $0.20 \mathrm{~g} / \mathrm{dL}$ lower $\mathrm{Hb}$ level than their non-anaemic peers did. The coefficient was more than twice the size for children born to mothers with moderate or severe pregnancy anaemia. Current HB of the mothers are consistently positively correlated with the child $\mathrm{Hb}$ levels, at a statistical significance level of 1\%. Testing for a U-shape relationship showed a positive, but decreasing correlation of pregnancy $\mathrm{Hb}$ and child $\mathrm{Hb}$, statistically significant at the $5 \%$ level (Panel C, table 2).

We did not find a statistically significant relationship of $\mathrm{Hb}$ or any type of pregnancy anaemia with the child development in general, or any specific dimension of development. The coefficients were small in magnitude, indicating indeed zero-effects, rather than an imprecise estimation. For cognitive development, we found a small, negative and weakly statistically significant association with $\mathrm{Hb}$ level during pregnancy and moderate or severe pregnancy anaemia. We found weak evidence for a U-shaped relationship between pregnancy $\mathrm{Hb}$ and cognitive skills, but not for motor, language or socioemotional skills.

The heterogeneity analyses showed that there were only small differences in the regressions of pregnancy $\mathrm{Hb}$ on 
Table 1 Summary statistics across exposure categories in the $\mathrm{Hb}$ sample

\begin{tabular}{|c|c|c|c|c|c|c|c|c|c|}
\hline & \multicolumn{3}{|c|}{ No preg. anaemia } & \multicolumn{3}{|c|}{ Mild preg. anaemia } & \multicolumn{3}{|c|}{$\begin{array}{l}\text { Moderate or severe preg. } \\
\text { anaemia }\end{array}$} \\
\hline & Mean & SD & $\mathbf{N}$ & Mean & SD & $\mathbf{N}$ & Mean & SD & $\mathbf{N}$ \\
\hline \multicolumn{10}{|l|}{ Outcome variables in 2017} \\
\hline $\mathrm{Hb}$ (child) & 10.97 & 1.35 & 292 & 10.71 & 1.23 & 305 & 10.26 & 1.39 & 344 \\
\hline Motor skills z-score & -0.02 & 1.04 & 284 & -0.04 & 1.00 & 298 & 0.07 & 0.93 & 335 \\
\hline Language skills z-score & 0.01 & 0.96 & 291 & -0.01 & 1.00 & 304 & 0.00 & 1.02 & 344 \\
\hline Cognition skills z-score & -0.01 & 0.99 & 290 & -0.04 & 1.02 & 304 & 0.07 & 0.97 & 340 \\
\hline Socioemo. skills z-score & 0.01 & 0.98 & 291 & -0.02 & 1.00 & 304 & -0.02 & 1.02 & 342 \\
\hline Height-for-age z-score & -2.36 & 1.39 & 287 & -2.40 & 1.27 & 300 & -2.54 & 1.34 & 338 \\
\hline Weight-for-age z-score & -1.91 & 1.10 & 286 & -1.94 & 1.05 & 294 & -2.07 & 1.08 & 339 \\
\hline Weight-for-height z-score & -0.98 & 1.47 & 288 & -0.97 & 1.71 & 300 & -0.98 & 1.60 & 338 \\
\hline Respiratory disease or fever & 0.20 & 0.40 & 291 & 0.21 & 0.41 & 305 & 0.20 & 0.40 & 344 \\
\hline Diarrhoea incidence & 0.24 & 0.43 & 287 & 0.25 & 0.43 & 304 & 0.26 & 0.44 & 344 \\
\hline \multicolumn{10}{|l|}{ Other child characteristics in 2017} \\
\hline Age of child (months) & 27.27 & 2.43 & 292 & 27.26 & 2.41 & 305 & 27.54 & 2.16 & 344 \\
\hline Currently breastfed & 0.44 & 0.50 & 292 & 0.46 & 0.50 & 305 & 0.44 & 0.50 & 344 \\
\hline Sex $($ male $=1)$ & 0.53 & 0.50 & 292 & 0.50 & 0.50 & 305 & 0.53 & 0.50 & 344 \\
\hline \multicolumn{10}{|l|}{ Pregnancy characteristics at baseline } \\
\hline $\mathrm{Hb}$ (preg.) & 11.76 & 0.72 & 292 & 10.44 & 0.29 & 305 & 8.68 & 1.07 & 344 \\
\hline $\begin{array}{l}\text { Gestational trimester during } \mathrm{Hb} \\
\text { (preg.) measurement }\end{array}$ & 1.89 & 0.76 & 292 & 2.01 & 0.69 & 305 & 2.16 & 0.69 & 344 \\
\hline First pregnancy & 0.22 & 0.42 & 292 & 0.22 & 0.41 & 305 & 0.19 & 0.40 & 344 \\
\hline Any ANC visits & 0.53 & 0.50 & 292 & 0.48 & 0.50 & 305 & 0.55 & 0.50 & 344 \\
\hline $\begin{array}{l}\text { Supplementary iron intake during } \\
\text { pregnancy }\end{array}$ & 0.61 & 0.49 & 292 & 0.60 & 0.49 & 305 & 0.57 & 0.50 & 344 \\
\hline $\begin{array}{l}\text { Other micronutrient intake during } \\
\text { pregnancy }\end{array}$ & 0.43 & 0.50 & 259 & 0.40 & 0.49 & 265 & 0.44 & 0.50 & 306 \\
\hline \multicolumn{10}{|l|}{ Mother characteristics } \\
\hline $\mathrm{Hb}$ (mother) in 2017 & 12.09 & 1.32 & 292 & 11.86 & 1.35 & 305 & 11.14 & 1.62 & 344 \\
\hline Mother can read at baseline & 0.25 & 0.43 & 292 & 0.27 & 0.44 & 305 & 0.24 & 0.43 & 344 \\
\hline Age of mother (years) at baseline & 24.65 & 3.66 & 292 & 24.90 & 3.89 & 305 & 24.67 & 3.93 & 344 \\
\hline \multicolumn{10}{|l|}{ Household characteristics } \\
\hline Food diversity index in 2017 & 7.01 & 1.50 & 292 & 7.30 & 1.46 & 305 & 7.10 & 1.52 & 344 \\
\hline Scheduled case or tribe at baseline & 0.29 & 0.46 & 284 & 0.29 & 0.46 & 295 & 0.33 & 0.47 & 331 \\
\hline $\begin{array}{l}\text { Improved sanitation facility at } \\
\text { baseline }\end{array}$ & 0.14 & 0.34 & 292 & 0.12 & 0.33 & 305 & 0.12 & 0.32 & 344 \\
\hline Asset index quintile at baseline & 3.09 & 1.44 & 292 & 3.01 & 1.42 & 305 & 2.85 & 1.45 & 344 \\
\hline
\end{tabular}

child $\mathrm{Hb}$ and skills by gestational trimester, caste category, maternal literacy, sex and ANC take-up (online supplemental table S1). In the case of language skills, we found a small, weakly statistically significant, negative interaction effect with ANC visits and a statistically significant, but positive interaction term for households belonging to a scheduled caste or tribe. Hence, for scheduled castes and tribes, we find evidence for a positive correlation of pregnancy anaemia and early language skills.
Our findings were robust to the inclusion of additional, potentially confounding, covariates, namely birth spacing, body-mass-index and postnatal depression, panchayat fixed effects and the exclusion of all covariates and fixed effects (online supplemental table S2 and 3). Robustness checks including gestational month instead of gestational trimester, and the subgroup analysis by gestational trimester also confirmed our main results (online supplemental table S4 and 5). We found no evidence for survival 
FREDI sample

\begin{tabular}{|c|c|c|c|}
\hline \multicolumn{2}{|c|}{ 1,918 pregnant women (2015) } & \multicolumn{2}{|c|}{ 1,918 pregnant women (2015) } \\
\hline & $\begin{array}{l}86 \text { household not home } \\
79 \text { households not located } \\
94 \text { households migrated } \\
10 \text { households refused } \\
211 \text { children no longer alive } \\
9 \text { children not living in the household }\end{array}$ & $\longrightarrow$ & $\begin{array}{l}86 \text { household not home } \\
79 \text { households not located } \\
94 \text { households migrated } \\
10 \text { households refused } \\
211 \text { children no longer alive } \\
9 \text { children not living in the household }\end{array}$ \\
\hline \multicolumn{2}{|c|}{ 1,429 women with children (2017) } & \multicolumn{2}{|c|}{ 1,429 women with children (2017) } \\
\hline$\rightarrow$ & 65 pregnancy $\mathrm{Hb}$ measures missing & $\longrightarrow$ & 65 pregnancy $\mathrm{Hb}$ measures missing \\
\hline - & $\begin{array}{l}143 \text { child's skill measures missing } \\
122 \text { maternal Hb measures missing } \\
100 \text { covariates missing } \\
\end{array}$ & $\rightarrow$ & \begin{tabular}{|l}
229 child's Hb measures missing \\
79 maternal Hb measures missing \\
115 covariates missing
\end{tabular} \\
\hline \multicolumn{2}{|c|}{$\begin{array}{l}999 \text { mother-child-dyad with } \\
\text { completed FREDI test (2017) }\end{array}$} & $\begin{array}{l}941 \text { moth } \\
\text { complete }\end{array}$ & $\begin{array}{l}\text { er-child-dyads with } \\
\mathrm{Hb} \text { profile (2017) }\end{array}$ \\
\hline
\end{tabular}

Figure 1 Attrition between 2015 (wave 1) and 2017 (wave 2) in childhood haemoglobin and skills sample.

bias, that is, that the surviving children were exposed to higher maternal $\mathrm{Hb}$ levels in-utero (online supplemental table S6).

Association of pregnancy anaemia and child health indicators We found no indication that suboptimal $\mathrm{Hb}$ levels during pregnancy were associated with stunting, wasting or
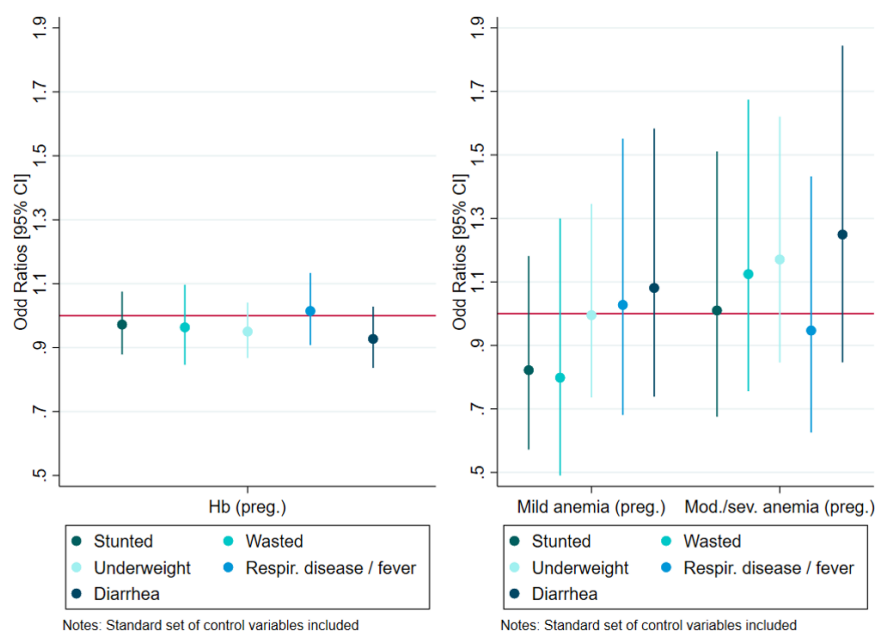

Figure 2 Weighted regression results on the association between maternal haemoglobin $(\mathrm{Hb})$ levels during pregnancy and growth and disease incidence indicators (ORs).

Table 2 Weighted regression results on the association between maternal haemoglobin $(\mathrm{Hb})$ levels and anaemia during pregnancy and early childhood development and childhood $\mathrm{Hb}$ levels

\begin{tabular}{|c|c|c|c|c|c|}
\hline & $\mathrm{Hb}$ (child) & Motor skills & Language skills & Cognition skills & Socioemo. skills \\
\hline $\mathrm{Hb}$ (preg) & $0.17^{\star \star \star}(0.11,0.23)$ & $-0.01(-0.05,0.03)$ & $-0.01(-0.05,0.04)$ & $-0.03^{\star}(-0.07,0.00)$ & $-0.02(-0.05,0.02)$ \\
\hline $\mathrm{R}^{2}$ & 0.174 & 0.246 & 0.218 & 0.303 & 0.321 \\
\hline \multicolumn{6}{|l|}{ Panel B } \\
\hline $\begin{array}{l}\text { Moderate/severe } \\
\text { preg. anaemia }\end{array}$ & $-0.57^{\star \star \star}(-0.78$ to -0.36$)$ & $0.06(-0.10,0.22)$ & $0.03(-0.12,0.19)$ & $0.12^{*}(-0.02,0.26)$ & $0.01(-0.12,0.15)$ \\
\hline $\mathrm{Hb}$ (mother) & $0.15^{\star \star \star}(0.08,0.22)$ & $0.01(-0.03,0.05)$ & $0.04^{*}(-0.01,0.08)$ & $0.06^{\star \star \star}(0.02,0.10)$ & $0.05^{\star \star}(0.00,0.09)$ \\
\hline $\mathrm{R}^{2}$ & 0.172 & 0.246 & 0.218 & 0.303 & 0.321 \\
\hline \multicolumn{6}{|l|}{ Panel C } \\
\hline $\mathrm{R}^{2}$ & 0.178 & 0.247 & 0.218 & 0.305 & 0.321 \\
\hline Controls & Yes & Yes & Yes & Yes & Yes \\
\hline Tester fixed effects & Yes & No & No & No & No \\
\hline FREDI fixed effects & No & Yes & Yes & Yes & Yes \\
\hline $\mathrm{N}$ & 939 & 972 & 996 & 990 & 994 \\
\hline
\end{tabular}

Outcome variables in columns (2)-(5) are standardised test scores and the coefficients are shown in SD. Panel $A$ uses pregnancy Hb level of the mother as main explanatory variable. In Panel $B$, the two explanatory variables of interest are mild pregnancy anaemia and moderate/severe pregnancy anaemia, while the omitted category is no pregnancy anaemia. In Panel C, the level of pregnancy $\mathrm{Hb}$ in quadratic from is included. $95 \%$ Cls using SEs clustered on village level are in parentheses. Included control variables: caste category, wealth quintile, food diversity in 2017, breast feeding status, maternal age and literacy, first pregnancy (dummy), gestational trimester during $\mathrm{Hb}$ (preg.) measurement, ANC visit (dummy), child's sex and age, and block dummies. Additional control variable in columns (2)-(5): test version. Tester fixed effects are anthropometric test conductor fixed effects. FREDI fixed effects are child development test conductor fixed effects. Haemoglobin is measured in g/L. Inverse probability weight accounting for attrition applied.

Conventional significance level: ${ }^{*} p<0.1,{ }^{* *} p<0.05,{ }^{* * *} p<0.01$. 
Table 3 Association of child's haemoglobin $(\mathrm{Hb})$ with their early skills and infectious disease incidence

\begin{tabular}{|c|c|c|c|}
\hline & Cum. development z-score & $\begin{array}{l}\text { Respiratory disease or } \\
\text { fever }\end{array}$ & Diarrhoea \\
\hline & Marginal effects & ORs & ORs \\
\hline $\mathrm{Hb}$ (mother) & $0.02(-0.01$ to 0.05$)$ & $1.00(0.89$ to 1.12$)$ & 0.98 (0.88 to 1.08$)$ \\
\hline (Adjusted) $\mathrm{R}^{2}$ & 0.334 & 0.061 & 0.047 \\
\hline FREDI fixed effects & Yes & No & No \\
\hline $\mathrm{N}$ & 915 & 938 & 933 \\
\hline
\end{tabular}

The outcome variable in column (1) is the standardised total test score and the coefficients are shown in SD. Outcomes in columns (2) and (3) are binary variables and the coefficient are shown as ORs. 95\% Cls using SEs clustered on village level are in parentheses. Included control variables: caste category, wealth quintile, food diversity in 2017, breast feeding, maternal age and literacy, first pregnancy (dummy), gestational trimester during $\mathrm{Hb}$ (preg.) measurement, ANC visit (dummy), child's sex and age, and block dummies. Additional control variable in column (1): test version. Tester fixed effects are anthropometric test conductor fixed effects. FREDI fixed effects are child development test conductor fixed effects. Haemoglobin is measured in $\mathrm{g} / \mathrm{L}$. Inverse probability weight accounting for attrition applied.

Conventional significance level: ${ }^{*} p<0.1,{ }^{* *} p<0.05,{ }^{* *} p<0.01$.

underweight of children, or increased the incidence of respiratory diseases or fever, or diarrhoea (figure 2).

\section{Association of childhood anaemia with child skills and health}

The lack of association between pregnancy anaemia, early skills and infectious diseases, despite the strong correlation with early $\mathrm{Hb}$ levels, might be an indication that childhood anaemia is not a risk factor for early childhood development or disease incidence in our study population. The cross-sectional analysis confirmed this hypothesis for diarrheal and respiratory diseases or fever (table 3). Yet, for the cumulative development scores, we found a small, positive and statistically significant coefficient.

\section{DISCUSSION}

\section{Interpretation}

Our cohort study from rural Bihar, India, shows a strong association between maternal $\mathrm{Hb}$ levels during pregnancy and the $\mathrm{Hb}$ levels of the offspring between 22 and 32 months after birth. The association is strongly statistically significant and robust to the inclusion of several, potentially confounding, variables, such as current nutritional status of the mother or child age. The relationship does not differ by child sex, caste category, gestational trimester, ANC take-up or maternal literacy. Moderate or severe pregnancy anaemia is associated with lower $\mathrm{Hb}$ levels of children than mild pregnancy anaemia. With increased pregnancy $\mathrm{Hb}$ level, the association with childhood $\mathrm{Hb}$ becomes weaker, yet in our sample, it does not reach the tipping point to a full reversal. This might be due to the small sample size on the higher end of the $\mathrm{Hb}$ spectrum.

Our analysis extends the current literature that connects pregnancy anaemia with direct birth outcomes in India, such as prematurity birth weight and size. ${ }^{42}$ The biological link between pregnancy anaemia and child anaemia more than 2 years after birth is unclear as the iron transferred from mother to child in-utero is typically consumed by the child's needs within the first year of life, before complementary feeding starts. ${ }^{14}$ Instead, our findings might be explained by a lower $\mathrm{Hb}$ trajectory since birth, initiated by the low $\mathrm{Hb}$ environment in-utero as has been found in another study for Benin..$^{15}$ It is also possible that the high rate of prolonged breastfeeding (44\% of the sample still being breastfed at the age of 2) hinders children with low iron stores at birth to catch up through an iron-rich diet. The negative association between continued breastfeeding, anaemia and iron deficiency of young children found in other studies supports this hypothesis. ${ }^{10} 44$

Overall, our findings on childhood anaemia are in line with a recent study from the USA, that showed an elevated risk ratio of infant anaemia from anaemia during pregnancy, in particular for moderate and severe anaemic conditions. ${ }^{18}$ Similarly, an analysis with data from China showed reduced $\mathrm{Hb}$ levels of infants for maternal anaemia during the 24-28 gestational week. The authors find however no association for pregnancy anemia in the first gestational trimester. ${ }^{19}$ The suggestive evidence for an inverse U-shaped relationship with childhood $\mathrm{Hb}$ is in line with findings on preterm birth and small-forgestational age as presented in a review of 19 studies across the world. ${ }^{8}$

We did not find any correlation between low $\mathrm{Hb}$ level during pregnancy and other child health outcomes, such as disease incidence or growth indicators. The disadvantage of children born to anaemic mothers, compared with their peers, hence seems to be limited to the low $\mathrm{Hb}$ levels. Our study does also not show any association between childhood $\mathrm{Hb}$ and infectious diseases, even though iron deficiency, a major cause of anaemia, is known to weaken the immune functions. ${ }^{45}$ In this regard, 
our findings contradict a study on Bedouin children in Israel, presenting a strong linkage between anaemia, diarrhoea and respiratory illnesses of children. ${ }^{46}$

Finally, we find no evidence that pregnancy anaemia is associated with lower early childhood development, even though children's Hb levels do correlate with early skills in our sample. Our results thereby go against the outcomes of several observational studies, most prominently, Chang $e t a l$ s analysis for rural China with children of a similar age. While they also did not find an association of pregnancy anaemia and psychomotor development, children of anaemic mothers showed lower scores in language and cognitive development when 18 and 24 months old. ${ }^{27}$ Differences in the socioeconomic characteristics of two study populations might explain this contrast. Not only did the mothers in Chang et $a$ 's study have higher levels of education, but the prevalence of childhood undernutrition among them was about a fifth of that in our study population. The poor nutritional status of children in Madhepura is likely not only a result of the insufficient intake of macronutrients and micronutrients but also of frequent gastrointestinal infections. The low coverage of improved toilet facilities and high prevalence of unsafe disposal of children's stool possibly led to greater exposure to faecal bacteria, thus facilitating the spread of diarrheal diseases and parasites. The constant exposure to faecal bacteria could also cause environmental enteropathy which hampers the absorption of nutrients and worsens malnutrition. ${ }^{47-49}$

Furthermore, it is important to note that the human brain development is largely driven by experience. ${ }^{50} \mathrm{~A}$ lack of adequate learning opportunities and stimulation in the early years can have long-lasting consequences for the functioning of the brain. ${ }^{51}{ }^{52}$ The stimulation environment created by the caregivers for their children is limited in our study area. Only about half of the caregivers told stories, sung songs or read a book to the children during the 3 days prior to the survey. About a quarter of the mothers reported that no household member had played with the child in that time.

Taken together, all of these lead us to argue that the additional, possible adverse impact of pregnancy anaemia on child development in our study setting was not large enough to be detectable in our estimations.

\section{Limitations}

Our analysis is based on the assumption that the single $\mathrm{Hb}$ measure taken at baseline is informative of the $\mathrm{Hb}$ status during the full course of pregnancy. Most $\mathrm{Hb}$ measurements of our participants were taken in the second trimester, allowing sufficient time for any improvement in the $\mathrm{Hb}$ levels during the remaining months. Such improvements after the baseline data collection would hence weaken the relationship of $\mathrm{Hb}$ that we measured with child outcomes. Given that half of the mothers in our sample reported not having consumed any iron supplements during pregnancy or received any ANC, we believe that the extent of such attenuation bias is limited.
The loss of follow-up of around half of the study children is reason for concern about the external validity of our findings. Despite weighting the study sample according to their inverse probably of attrition, we are only able to correct for observable differences in the study population and the lost observations. If the unobserved characteristics which caused the loss in follow-up also correlated with the explanatory and outcome variables, the results of our analysis would be biased.

Any systematic error in $\mathrm{Hb}$ measurement, depending on the $\mathrm{Hb}$ level, could be a bigger concern. This could have been induced by the differential recommendations our field team gave based on the blood test results. However, our data do not support this hypothesis. We did not observe a particular behaviour change in more severely anaemic women: even after delivery only $57 \%$ of the women with moderate or severe pregnancy anaemia reported consuming iron supplements during pregnancy, compared with $60 \%-61 \%$ in the mildly and non-anaemic group. During pregnancy, the reported supplementation rates across the groups were aswell similar $(16 \%$ of the moderately or severely anaemic women versus $19 \%-20 \%$ of the mildly or non-anaemic women). This suggests that the advice given by the field teams upon anaemia detected did not alter the women's behaviour.

Two additional points should be kept in mind when interpreting our findings. First, we collected $\mathrm{Hb}$ levels but not ferritin levels, which leaves room for speculation on the origin of anaemia in the study sample. Although iron deficiency is commonly believed to be the major reason for anaemia, to the best of our knowledge, no study has documented the actual share of iron deficiency anaemia among the anaemic pregnant women in rural Bihar. Second, it should be noted that the share of severely anaemic pregnant women in our study is very small. The association of moderate or severe anaemia with child development is hence mainly attributable to the group of women who were moderately anaemic during pregnancy.

\section{CONCLUSION}

We find strong, yet not causal, evidence that pregnancy anaemia is a risk factor for childhood anaemia but not for any deficiency in the development of early skills, on average. The relationship between pregnancy anaemia and childhood $\mathrm{Hb}$ grows stronger with lower levels of Hb during pregnancy. Yet, diarrhoea or respiratory disease or fever incidence or child growth is not affected by either childhood $\mathrm{Hb}$ or pregnancy Hb. This study gives important insights into the consequences of pregnancy anaemia for populations underserved by ANC services and with high rates of malnutrition. Nevertheless, using a singular $\mathrm{Hb}$ measurement during pregnancy and facing high rate of attrition between the waves might affect the external validity of our results. Nevertheless, the strong association between pregnancy anaemia and childhood anaemia we identified in this study should be further investigated to observe 
if it will affect later life outcomes, commonly associated with iron deficiency and anaemia.

\section{Twitter Malavika A Subramanyam @MalavikaSocEpi}

Acknowledgements The authors acknowledge the immensely helpful contribution during the data collections and advice of Cara Ebert, Abhijeet Kumar and Mareike Schön. We further acknowledge support by the Open Access Publication Funds of the University of Göttingen.

Contributors EH, MS and SV designed research and the survey instruments, CM designed the child skill assessment. SV and MS coordinated the first wave data collection, EH coordinated the second wave data collection, with support of $\mathrm{CM}$ for the child skill assessment. EH analysed the data and wrote the first draft of the manuscript. All authors provided input to the manuscript and approved the final version. EH is the guarantor.

Funding The study was approved by the ethics board of the IIT Gandhinagar (IEC/2014-15/2/MS /MS/006, IEC/2016-17/2/MS /MS/025) and the University of Goettingen (no IRB number available). We obtained written informed consent for the interviews, growth measurements, blood sample collections and the child development testing during each wave.

Competing interests None declared.

Patient consent for publication Not required.

Ethics approval This work was supported by the German Research Foundation (DFG) (Research Training Group 1723) and 3ie International Initiative for Impact Evaluation (CPW.01.GV.IE). The study was prepared in parts during the PhD Fellowship at the United Nations University World Institute for Development Economic Research (UNUWIDER).

Provenance and peer review Not commissioned; externally peer reviewed.

Data availability statement Data access can be obtained through reasonable request from the corresponding authors. Data is not yet available to the public.

Supplemental material This content has been supplied by the author(s). It has not been vetted by BMJ Publishing Group Limited (BMJ) and may not have been peer-reviewed. Any opinions or recommendations discussed are solely those of the author(s) and are not endorsed by BMJ. BMJ disclaims all liability and responsibility arising from any reliance placed on the content. Where the content includes any translated material, BMJ does not warrant the accuracy and reliability of the translations (including but not limited to local regulations, clinical guidelines, terminology, drug names and drug dosages), and is not responsible for any error and/or omissions arising from translation and adaptation or otherwise.

Open access This is an open access article distributed in accordance with the Creative Commons Attribution Non Commercial (CC BY-NC 4.0) license, which permits others to distribute, remix, adapt, build upon this work non-commercially, and license their derivative works on different terms, provided the original work is properly cited, appropriate credit is given, any changes made indicated, and the use is non-commercial. See: http://creativecommons.org/licenses/by-nc/4.0/.

ORCID iD

Esther Heesemann http://orcid.org/0000-0001-9453-035X

\section{REFERENCES}

1 Morgane PJ, Austin-LaFrance R, Bronzino J, et al. Prenatal malnutrition and development of the brain. Neurosci Biobehav Rev 1993;17:91-128.

2 Stevens GA, Finucane MM, De-Regil LM, et al. Global, regional, and national trends in haemoglobin concentration and prevalence of total and severe anaemia in children and pregnant and nonpregnant women for 1995-2011: a systematic analysis of populationrepresentative data. Lancet Glob Health 2013;1:e16-25.

3 Allen LH. Biological mechanisms that might underlie iron's effects on fetal growth and preterm birth. J Nutr 2001;131:581S-9.

4 Burke RM, Leon JS, Suchdev PS. Identification, prevention and treatment of iron deficiency during the first 1000 days. Nutrients 2014;6:4093-114.

5 De Pee S, Bloem MW, Sari M, et al. The high prevalence of low hemoglobin concentration among Indonesian infants aged 3-5 months is related to maternal anemia. J Nutr 2002;132:2215-21.

6 Shao J, Lou J, Rao R, et al. Maternal serum ferritin concentration is positively associated with newborn iron stores in women with low ferritin status in late pregnancy. J Nutr 2012;142:2004-9.
7 Rahman MM, Abe SK, Rahman MS, et al. Maternal anemia and risk of adverse birth and health outcomes in low- and middle-income countries: systematic review and meta-analysis. Am J Clin Nutr 2016;103:495-504

8 Dewey KG, Oaks BM. U-shaped curve for risk associated with maternal hemoglobin, iron status, or iron supplementation. Am J Clin Nutr 2017;106:1694S-702.

9 Balarajan Y, Ramakrishnan U, Özaltin E, et al. Anaemia in low-income and middle-income countries. The Lancet 2011;378:2123-35.

10 Pasricha S-R, Black J, Muthayya S, et al. Determinants of anemia among young children in rural India. Pediatrics 2010;126:e140-9.

11 Georgieff MK. Iron deficiency in pregnancy. Am J Obstet Gynecol 2020;223:516-24.

12 Lozoff B. Iron deficiency and child development. Food Nutr Bull 2007;28:S560-71.

13 Lukowski AF, Koss M, Burden MJ, et al. Iron deficiency in infancy and neurocognitive functioning at 19 years: evidence of long-term deficits in executive function and recognition memory. Nutr Neurosci 2010;13:54-70.

14 Chaparro CM. Setting the stage for child health and development: prevention of iron deficiency in early infancy. $J$ Nutr 2008;138:2529-33.

15 Koura KG, Ouédraogo S, Cottrell G, et al. Maternal anaemia at delivery and haemoglobin evolution in children during their first 18 months of life using latent class analysis. PLoS One 2012;7:e50136.

16 Abioye Al, McDonald EA, Park S, et al. Maternal anemia type during pregnancy is associated with anemia risk among offspring during infancy. Pediatr Res 2019;86:396-402.

17 Kumar A, Rai AK, Basu S, et al. Cord blood and breast milk iron status in maternal anemia. Pediatrics 2008;121:e673-7.

18 Leslie MS, Park J, Briggs LA, et al. Is anemia in low income pregnant women related to their infants' having anemia? a cohort study of pregnant Women-Infant pairs in the United States. Matern Child Health J 2020;24:768-76.

19 Zhang Y, Jin L, Liu J-M, et al. Maternal hemoglobin concentration during gestation and risk of anemia in infancy: secondary analysis of a randomized controlled trial. J Pediatr 2016;175:106-10.

20 Janbek J, Sarki M, Specht IO, et al. A systematic literature review of the relation between iron status/anemia in pregnancy and offspring neurodevelopment. Eur J Clin Nutr 2019;73:1561-78.

21 McCann S, Perapoch Amadó M, Moore SE. The role of iron in brain development: a systematic review. Nutrients 2020;12:2001.

22 Angulo-Barroso RM, Li M, Santos DCC, et al. Iron supplementation in pregnancy or infancy and motor development: a randomized controlled trial. Pediatrics 2016;137:e20153547.

23 Santos DCC, Angulo-Barroso RM, Li M, et al. Timing, duration, and severity of iron deficiency in early development and motor outcomes at 9 months. Eur J Clin Nutr 2018;72:332-41.

24 Tran TD, Tran T, Simpson JA, et al. Infant motor development in rura Vietnam and intrauterine exposures to anaemia, iron deficiency and common mental disorders: a prospective community-based study. BMC Pregnancy Childbirth 2014;14:8.

25 Hanieh S, Ha TT, Simpson JA, et al. Effect of low-dose versus higher-dose antenatal iron supplementation on child health outcomes at 36 months of age in Viet Nam: longitudinal followup of a cluster randomised controlled trial. BMJ Glob Health 2017;2:e000368.

26 Tran TD, Biggs B-A, Tran T, et al. Impact on infants' cognitive development of antenatal exposure to iron deficiency disorder and common mental disorders. PLoS One 2013;8:e74876.

27 Chang S, Zeng L, Brouwer ID, et al. Effect of iron deficiency anemia in pregnancy on child mental development in rural China. Pediatrics 2013;131:e755-63.

28 Parsons AG, Zhou SJ, Spurrier NJ, et al. Effect of iron supplementation during pregnancy on the behaviour of children at early school age: long-term follow-up of a randomised controlled trial. Br J Nutr 2008;99:1133-9.

29 Zhou SJ, Gibson RA, Crowther CA, et al. Effect of iron supplementation during pregnancy on the intelligence quotient and behavior of children at $4 \mathrm{Y}$ of age: long-term follow-up of a randomized controlled trial. Am J Clin Nutr 2006;83:1112-7.

30 IIPS. National family health survey 2015-16 district fact sheet Madhepura Bihar, 2017. Available: http://rchiips.org/NFHS/FCTS/BR/ BR_FactSheet_213_Madhepura.pdf

31 Yadav K, Kant S, Ramaswamy G, et al. Validation of point of care hemoglobin estimation among pregnant women using digital Hemoglobinometers (HemoCue 301 and HemoCue 201+) as compared with Auto-Analyzer. Indian J Hematol Blood Transfus 2020;36:342-8.

32 Sharma JB, Shankar M. Anemia in pregnancy. JIMSA 2010;23:253-60. 
33 World Health Organization. Haemoglobin concentrations for the diagnosis of anaemia and assessment of severity. Geneva: World Health Organization, 2011. http://www.who.int/vmnis/indicators/ haemoglobin.pdf

34 Albers CA, Grieve AJ. Test review: Bayley, N. (2006). Bayley scales of infant and toddler Development- third edition. San Antonio, tx: Harcourt assessment. J Psychoeduc Assess 2007;25:180-90.

35 Mähler C, Cartschau F, Rohleder K. Frühkindliche Entwicklungsdiagnostik für Kinder von 0-3 Jahren (FREDI 0-3). Hogrefe: Goettingen, 2016.

36 Hasselhorn M. FREDI 0-3. Frühe Bildung 2017;6:101-3.

37 World Health Organization, UNICEF. WHO child growth standards and the identification of severe acute malnutrition in infants and children: a joint statement by the World Health Organization and the United Nations Children's Fund, 2009. Available: http://www.ncbi. nlm.nih.gov/books/NBK200775/ [Accessed 26 Sep 2020].

38 Barcellos SH, Carvalho LS, Lleras-Muney A. Child gender and parental investments in India: are boys and girls treated differently? Am Econ J Appl Econ 2014;6:157-89.

39 Ebert C, Vollmer S. Child-specific son preference, birth order and cognitive skills in early childhood. Courant Research Centre "Poverty, Equity and Growth.”, 2019.

40 Fitzgerald J, Gottschalk P, Moffitt R. An analysis of sample attrition in panel data: the Michigan panel study of income dynamics. Working paper. National Bureau of Economic Research, 1998.

41 Mireku MO, Davidson LL, Koura GK, et al. Prenatal hemoglobin levels and early cognitive and motor functions of One-Year-Old children. Pediatrics 2015;136:e76-83.

42 Nair M, Choudhury MK, Choudhury SS, et al. Association between maternal anaemia and pregnancy outcomes: a cohort study in Assam, India. BMJ Glob Health 2016;1:e000026.
43 Patel A, Prakash AA, Das PK, et al. Maternal anemia and underweight as determinants of pregnancy outcomes: cohort study in eastern rural Maharashtra, India. BMJ Open 2018;8:10.1136/ bmjopen-2018-021623.

44 Maguire JL, Salehi L, Birken CS, et al. Association between total duration of breastfeeding and iron deficiency. Pediatrics 2013;131:e1530-7.

45 Ekiz C, Agaoglu L, Karakas Z, et al. The effect of iron deficiency anemia on the function of the immune system. Hematol $J$ 2005;5:10.1038/sj.thj.6200574:579-83.

46 Levy A, Fraser D, Rosen SD, et al. Anemia as a risk factor for infectious diseases in infants and toddlers: results from a prospective study. Eur J Epidemiol 2005;20:277-84.

47 Kosek MN, Ahmed T, Bhutta Z, MAL-ED Network Investigators. Causal pathways from enteropathogens to environmental enteropathy: findings from the MAL-ED birth cohort study. EBioMedicine 2017;18:109-17.

48 Ngure FM, Reid BM, Humphrey JH, et al. Water, sanitation, and hygiene (wash), environmental enteropathy, nutrition, and early child development: making the links. Ann N Y Acad Sci 2014:1308:118-28.

49 Watanabe K, Petri WA. Environmental enteropathy: elusive but significant subclinical abnormalities in developing countries. EBioMedicine 2016;10:25-32.

50 Knudsen El. Sensitive periods in the development of the brain and behavior. J Cogn Neurosci 2004;16:1412-25.

51 Prado EL, Dewey KG. Nutrition and brain development in early life. Nutr Rev 2014;72:267-84

52 Walker SP, Wachs TD, Grantham-McGregor S, et al. Inequality in early childhood: risk and protective factors for early child development. Lancet 2011;378:1325-38. 